\title{
A segurança do trabalho na construção civil
}

Victor Guimarães Salum Zago; Fabiana Souza Caetano; Fernando Henrique Silva Melo; Thainara Rodrigues Souza; Fabiola Eugênio Arrabaça Moraes.

Uniube - Universidade de Uberaba

victor.salum@hotmail.com / fabiola.moraes@uniube.com

\section{1 - Introdução}

A construção civil é um setor de grande empregabilidade e de grande demanda no Brasil. É considerado um dos serviços laborais com maior potencial de risco a saúde em todo o mundo. Dentre as maiores causas de morte na construção civil, encontram-se os acidentes de trabalho. De acordo com dados estatísticos do Ministério da Previdência Social (MPS), o setor da construção civil registrou 59.808 acidentes de trabalho em 2011, comparado aos dados de 2010, o crescimento foi de $6,9 \%$ maior.

A temática Segurança do Trabalho perfaz uma importante discussão na perspectiva globalizada que envolve as diversas áreas de análise da Engenharia Civil, sendo concomitantemente imprescindível em qualquer área laboral.

A saúde dos profissionais que desenvolvem tais atividades está diretamente ligada ao perfil do trabalho e ao modo como são executadas as técnicas e manejo dos equipamentos de trabalho. Apesar da importância da aplicação de técnicas e normas de segurança o setor de construção civil tem se mostrado o responsável por diversas mortes e incapacitação em seus trabalhadores. Segundo dados do Ministério da Previdência Social (MPS), o número de óbitos registrados no ano de 2010 foi de 2.712 .

Um planejamento direto e especifico acerca das medidas de segurança a ser implementada nas diversas áreas da construção civil, consiste no melhor meio para promover a segurança dos profissionais, principalmente a se considerar essa área de trabalho com grandes potenciais de acidentes.

Diante dos aspectos abordados, surge uma indagação pertinente ao tema: Quais aspectos levam a não concretização das estratégias de segurança no trabalho? De que forma essas estratégias devem ser implementadas? Porque apesar de grande aparato técnico e conhecimento especifico na temática, fatalidades são comumente encontradas nos canteiros de obras? Aspectos profissionais podem ser qualificados como causas facilitadoras para a não adesão das estratégias de segurança? E 0 trabalhador cumpre as normas de Segurança do Trabalho que são implementadas pelas empresas e pelos órgãos competentes?

Diante dessas inquietações, 0 presente estudo busca resposta para tais indagações através da revisão de literatura, com analise em diversos artigos científicos com temática relacionada, através de uma busca sistemática.

Assim, tendo como base a NR-18 que afirma regularizar os elementos de decisões a serem efetuadas, em função das metas de uma obra, salientando os riscos de acidentes e doenças do trabalho e as suas medidas de segurança.

\section{2 - Materiais e métodos}

O presente estudo trata-se de uma pesquisa de revisão bibliográfica que terá como base uma abordagem qualitativa, que buscará traduzir as informações coletadas em artigos sobre os fatores que interferem na aplicação de implementação estratégias de segurança na construção civil. A pesquisa apresenta caráter exploratório e descritivo visando respectivamente, proporcionar mais informações sobre o tema abordado, registrando, analisando, classificando e interpretando os dados obtidos através de revisão bibliográfica.

Serão coletados artigos da base de dados CAPES e SCIELO com publicações sem rigor de tempo. Os seguintes descritores serão usados: construção civil, segurança do trabalho, segurança na construção, acidentes de trabalho, prevenção de acidentes e, idioma texto em português. A busca foi realizada por meio das palavras encontradas nos títulos e nos resumos dos artigos.

Utilizou-se também de teses de mestrado e doutorado encontrados em sites de universidades brasileiras, assim como

www.uniube.br/entec - UNIUBE Campus Aeroporto - Uberaba/MG 
8을 EnTec - Encontro de Tecnologia da UNIUBE / 28 a 30 de outubro de 2014

literaturas inerentes a temática de saúde do trabalhador.

Em posse dos artigos, foram feitos fichamentos dos mesmos a ponto de levantar as características mais pertinentes à temática, as possíveis causas que levam aos acidentes nas construções civis, a frequência e intensidade, subsequente foram formulados a problemática e os objetivos.

O estudo exploratório e descrito combinado tem por objetivo descrever completamente o fenômeno com análises empíricas e/ou teóricas. Apresentam-se em abordagens qualitativas e/ou quantitativas com informações explícitas e os procedimentos de amostragem são flexíveis. (MARCONI; LAKATOS, 1990)

Por fim, foram desenvolvidos os resultados e conclusões, ao qual apresentaram as principais causas dos acidentes de trabalho em construções civis, e quais os fatores contribuem para a implementação parcial ou ausente das estratégias de segurança do trabalho.

\section{3 - Resultados e discussão}

A) Resultados esperados para o período ago/2014-jul/2015

- conhecer as estratégias atuais de segurança na construção civil.

- identificar os fatores que influenciam a não aplicação das estratégias de segurança no setor da construção civil.

B) Resultados esperados para o período ago/2015-jul/2016

- publicação do artigo em revistas eletrônica e/ou periódicos.

- publicação do artigo em congressos com área afim a temática.

\section{4 - Considerações finais}

Com as informações levantadas na pesquisa, será possível a implementação de medidas e normas de segurança que priorizem a boa saúde e a integridade física e a vida dos trabalhadores, sendo assim este projeto contribui para o enriquecimento pessoal de todos os profissionais envolvidos nas obras de engenharia civil, de forma abrangente e esclarecedora, sobre dúvidas acerca dos riscos à saúde e a suas respectivas medidas cabíveis, tornando assim
0 trabalho mais seguro e melhorando 0 desempenho profissional.

\section{5 - Referências}

ARVALHO, Verbena Duarte Brito de. A segurança do trabalho na industria da construção civil. 1984. 83 f. Dissertação (Mestrado) - Curso de Arquitetura, Departamento de Departamento de Engenharia Civil, Universidade Federal do Rio Grande do Sul, Porto Alegre, 1984.

DUL, Jan. Ergonomia prática. São Paulo: Blucher, 1995.

FERREIRA, Renata Rivera; MENDES, René. Alguns aspectos epidemiológicos dos acidentes de trabalho fatais ocorridos em campinas, SP. Rev. Saúde Publica, S. Paulo, p.251-262, 1981.

Guia Trabalhista. NR 18: Condições e meio ambiente de trabalho na indústria da construção. Disponível em: <http://www.guiatrabalhista.com.br/legislacao/ nr/nr18.htm>. Acesso em: 21 out. 2014.

MARCONI, M. A.; LAKATOS, E. M. Técnicas de Pesquisa. 2. ed. São Paulo: Atlas, 1990.

SANTANA, Vilma S. and OLIVEIRA, Roberval $P$. Saúde e trabalho na construção civil em uma área urbana do Brasil. Cad. Saúde Pública [online]. 2004, vol.20, n.3, pp. 797$811 . \quad$ ISSN 0102-311X. http://dx.doi.org/10.1590/S0102$311 \times 2004000300017$.

\section{Agradecimentos}

À instituição Uniube - Universidade de Uberaba pela realização das medidas ou empréstimo de equipamentos e disponibilização dos arquivos de pesquisa. 